\title{
MAPA DE SUSTENTABILIDADE TERRITORIAL GERADO POR TÉCNICAS DE GEOPROCESSAMENTO E DE SENSORIAMENTO REMOTO
}

\section{TERRITORIAL SUSTAINABILITY MAP GENERATED USING GEOPROCESSING AND REMOTE SENSING TECHNIQUES}

\author{
Nascimento, P. S. R ${ }^{1}$; Garcia, G. J. ${ }^{2}$ \\ ${ }^{1}$ Engenheiro Geólogo, Prof. Dr. das Faculdades ASMEC Ouro Fino \\ Av. Prof. ${ }^{\circ}$ Dr. Antonio Eufrásio de Toledo, 100 - Jardim dos Ipês Ouro Fino-MG \\ psrn_ambiental@yahoo.com.br \\ ${ }^{2}$ Engenheiro Agrônomo, Prof. Dr. da Universidade Estadual Paulista - CEAPLA, \\ Av. 24A, 1515 - Rio Claro - SP - e-mail: gilberto@rc.unesp.br
}

\section{RESUMO}

O objetivo deste trabalho é gerar um mapa de sustentabilidade territorial utilizando técnicas de sensoriamento remoto e geoprocessamento da Sub-bacia do Baixo Piracicaba (SP), pela integração automática dos mapas de vulnerabilidade e favorabilidade à erosão. De acordo com os resultados obtidos, a área de estudo é suscetível a processos erosivos que podem ser minimizados por medidas de recomposição da mata ciliar do rio Piracicaba e reflorestamento das encostas das serras de São Pedro e Itaqueri.

Palavras-chave: geoprocessamento, sensoriamento remoto, sustentabilidade territorial, vulnerabilidade à erosão, favorabilidade à erosão.

\begin{abstract}
The objective of this study is to generate a map of territorial sustainability using techniques of Remote Sensing and Geoprocessing in the Sub-basin of the lower Piracicaba River (SP), through the automatic integration of the erosion vulnerability and favorability maps. Findings showed that the area is susceptible to erosive processes which can be minimized using methods of riparian forest restoration of the
\end{abstract}


river Piracicaba and reforestation of the hillsides of São Pedro and Itaqueri mountain ranges.

Key words: geoprocessing, remote sensing, territorial sustainability, erosion vulnerability, erosion favorability.

\section{INTRODUÇÃO}

O conhecimento do potencial da superfície terrestre em sustentar os diferentes usos da terra é imprescindível para o monitoramento de fenômenos geodinâmicos indesejáveis, como a erosão e assoreamento, dentre outros, os quais são naturais ou induzidos pela ocupação territorial. Neste contexto, reconhecer as limitações e aptidões desse meio é um mecanismo eficiente de análise ambiental, pois as estratégias para o desenvolvimento ecologicamente correto baseiam-se na avaliação da capacidade de sustentação do território e da sua recuperação frente à atividade humana. Assim, a organização territorial permite uma análise mais detalhada do uso da terra e a colocação de propostas mais apropriadas ao crescimento econômico de seus habitantes, em consonância com as condições naturais.

Atualmente, a abordagem de análise ambiental utiliza-se da bacia hidrográfica como a unidade territorial básica de referência e de diversos critérios metodológicos, com o intuito de compartimentar a sustentabilidade territorial de uma determinada área.

Muitos estudos tem sido desenvolvidos, neste sentido, na avaliação das rochas, de solos, do relevo, da vegetação natural e do uso da terra, da erosividade e da drenagem. E, no processamento e operacionalização destes dados, há diversos procedimentos de espacialização e individualização de unidades do meio físico, principalmente utilizando técnicas de sensoriamento remoto e de geoprocessamento.

A estrutura produtiva da Sub-bacia do Baixo Piracicaba (SP) está ligada à agricultura parcialmente mecanizada, que se encontra em processo de intensificação e otimização. $\mathrm{O}$ desenvolvimento da agroindústria ocorre com o apoio da rede de transporte, que permite a interligação com todo o Estado. Esta área é umas das regiões mais suscetíveis aos processos erosivos e de assoreamento da Bacia Hidrográfica do Rio Piracicaba. A geologia e o clima condicionaram as feições geomorfológicas, pedológicas, hidrológicas e fitológicas e delinearam as particularidades dos diferentes tipos de paisagens e das possibilidades de atividades humanas nesta área.

Neste contexto, o objetivo deste trabalho é elaborar o mapa de sustentabilidade territorial da Sub-bacia do Baixo Piracicaba pelo método determinístico booleano, a partir das classes dos mapas de vulnerabilidade e favorabilidade à erosão. Este último é definido a partir do grau de dissecação do relevo (densidade de drenagem) e da 
capacidade da chuva em provocar erosão (erosividade). Já o primeiro é determinado pela morfodinâmica da paisagem a partir da integração das características litológicas, declividade, formas de relevo, tipos de solos e coberturas vegetais naturais e uso da terra.

\section{SENSORIAMENTO REMOTO E SISTEMA DE INFORMAÇÃO GEOGRÁFICA}

A análise conjugada dos componentes da natureza pode ser realizada quando utilizadas técnicas de sensoriamento remoto e geoprocessamento na identificação, interpretação visual dos alvos da superfície terrestre e na integração de dados. Desta forma, para o entendimento da dinâmica do meio ambiente é essencial o uso de sistemas de alta capacidade para o tratamento e análises de informações multitemáticas (EMBLETON e LIEDTKE, 1990).

As técnicas de sensoriamento remoto proporcionam a elaboração e atualização de mapas com maior rapidez e economia (ASRAR, 1989). As imagens orbitais podem ser processadas por algoritmos que visam melhorar a fidelidade da cena para as análises visual e automática para obter o produto desejado (SCHOWENGERDT, 1983).

As ferramentas de um SIG (Sistema de Informação Geográfica) permitem realizar operações analíticas em grandes conjuntos de dados, como a combinação de vários mapas com intuito de obter informações da superfície terrestres diferenciadas.

Dentre as várias operações utilizadas em mapas digitais, destacam-se as técnicas determinísticas (método booleano e média aritmética), que quantificam os pesos das classes dos mapas em valores absolutos (WESTEN et al., 2000), utilizandose de álgebras de mapas, que produz novos dados a partir de funções de manipulações aplicadas a um ou a mais mapas. Outro método é a geoestatística, que utiliza inferências a partir de lógica bivariada, como a krigagem, que produz mapas com excelente precisão gráfica (CAMARGO et al. 2004).

\section{ASPECTOS GERAIS DA ÁREA DE ESTUDO}

A área de estudo situa-se na região central paulista, à nordeste da Bacia Sedimentar do Paraná neste Estado, delimitada pelos paralelos $22^{\circ} 15^{\prime}$ a $22^{\circ} 45^{\prime}$ de latitude Sul e pelos meridianos $47^{\circ} 45^{\prime}$ a $48^{\circ} 30^{\prime}$ de longitude Oeste (Figura 1).

A geologia é representada pelas rochas dos grupos Passa Dois (Formação Corumbataí), São Bento (Formações Pirambóia, Botucatu e Serra Geral) e Coberturas Cenozóicas (Formação Itaqueri e Aluviões Arenosos). Estas formações estão embutidas nas províncias geomorfológicas denominadas de Depressão Periférica e Cuesta Basáltica (ALMEIDA et al., 1981; PONÇANO et al., 1981), constituídas por 
Planícies Fluviais, Topos Tabulares de Dissecação Baixa e Muito Baixa e Topos Convexos de Dissecação Muito Alta, Média a Alta e Dissecação Baixa. Os tipos de solos, de acordo com o Sistema Brasileiro de Classificação (EMBRAPA, 1999), são representados pelas seguintes classes: NEOSSOLO QUARTZARÊNICO, GLEISSOLO TIOMÓRFICO, ARGISSOLO VERMELHO-AMARELO e LATOSSOLO VERMELHO-AMARELO (OLIVEIRA et al., 1999).

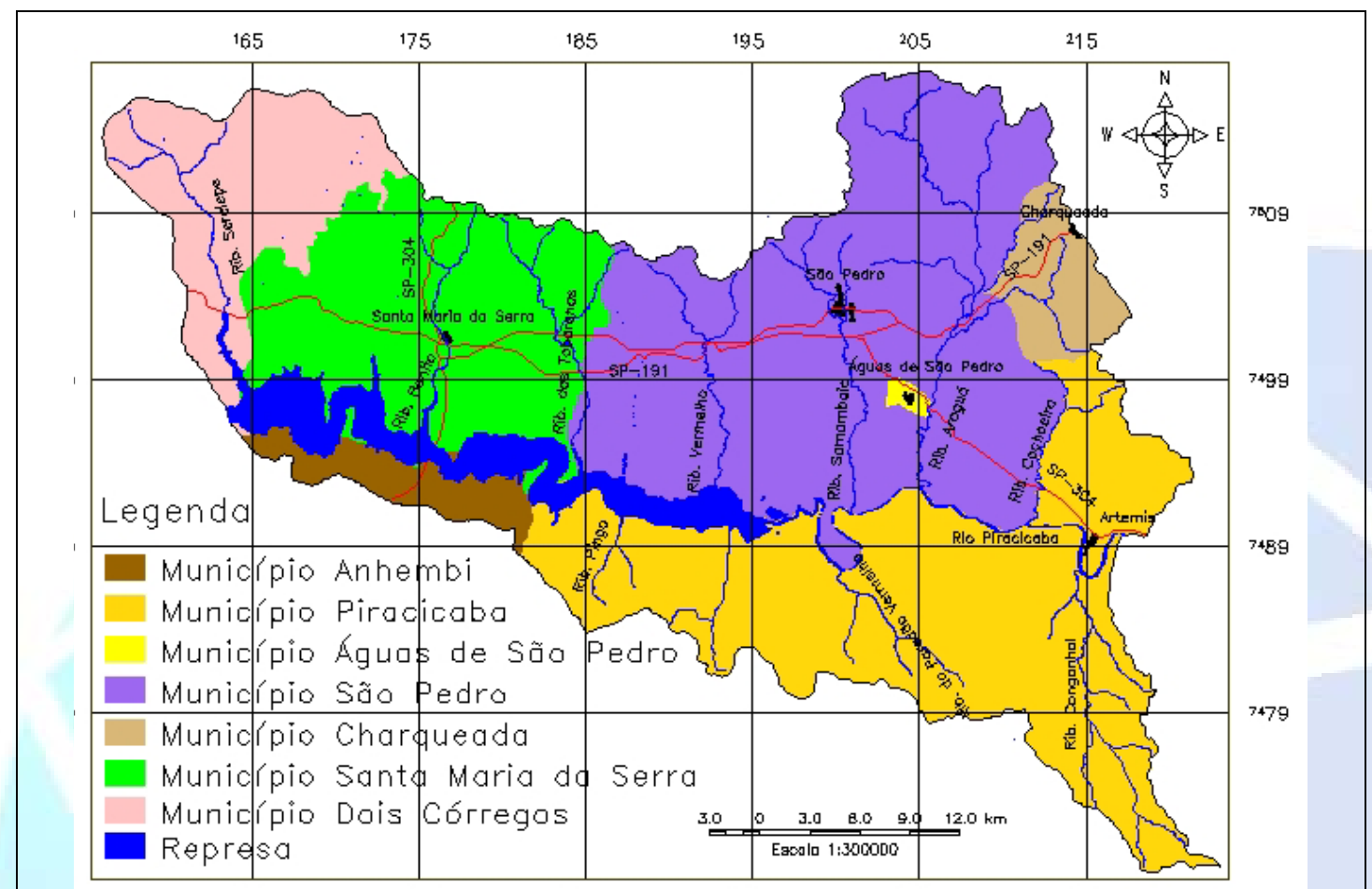

Figura 1- Localização da área de estudo.

A precipitação pluviométrica está entre 1.100 e $1.800 \mathrm{~mm}$ e temperaturas médias de 18 a $22^{\circ} \mathrm{C}$ (MONTEIRO, 2000). A cobertura vegetal é constituída por Floresta de Várzea, Floresta Estacional Semi-decidual, Capoeira e Cerrado. As categorias de uso da terra são as Culturas Perenes (café e fruticultura), Anuais (hortigranjeiras) e Bienal (cana-de-açúcar) e Pastagem (SÃO PAULO, 1999).

\section{MATERIAL}

Os materiais utilizados para o desenvolvimento deste trabalho foram as cartas topográficas do IBGE na escala 1:50.000 (Folhas de Dois Córregos, Brotas, Itirapina, Piracicaba, Capivari, Laras, São Pedro, Barra Bonita e Santa Maria da Serra); imagem TM/Landsat-5 multiespectral referentes à órbita e ponto 220/73, passagem de 27 de julho de 2002; mapas temáticos: Mapa Geológico (ALMEIDA et al., 1981), Mapa Geomorfológico (ROSS e MOROZ, 1997), Mapa Pedológico (OLIVEIRA et al., 1999) e Mapa de Erosividade (CAVALLI, 1999) e o programa computacional de 
geoprocessamento SPRING-Versão 4.1 (Sistema de Processamento de Informações Georreferenciadas), desenvolvido pelo Instituo Nacional de Pesquisas Espaciais (INPE).

\section{MÉTODO}

\subsection{Importação da Base Cartográfica e das Imagens no SPRING}

A base cartográfica foi composta pelas cartas topográficas do IBGE citadas anteriormente e representada pelo Sistema de Coordenadas de Projeção UTM/Córrego Alegre, no formato digital dxf. Assim, foi importada diretamente para o SPRING, por um conversor automático para o formato $\mathrm{spr}$ (formato de armazenamento vetorial do SPRING). As imagens TM/Landsat-5, ao serem importadas, foram projetadas para o sistema de coordenadas da base cartográfica. Estas imagens, em formato GeoTIFF, foram convertidas automaticamente para o formato GRIB (formato de importação e armazenamento de imagens no SPRING).

\section{2. Mapas de Geologia, Geomorfologia, Pedologia e Erosividade.}

Os mapas geológico, geomorfológico, pedológico e de erosividade foram digitalizados manualmente no formato analógico. As legendas originais foram utilizadas.

\subsection{Mapas de Classes de Declividade e de Cobertura Vegetal e Uso da Terra}

O mapa de classes de declividade foi feito por processamento automático através de máscaras móveis, pela função de derivação na vizinhança de cada célula para toda a área de interesse, desde a geração das grades triangular e retangular até o fatiamento, que consiste em gerar uma imagem temática a partir de uma grade de declividade.

O mapa de cobertura vegetal e uso da terra foi elaborado pela análise interpretativa de imagens digitais. Para facilitar a discriminação dos alvos realizaramse alguns pré-processamentos nas imagens (expansão de contraste e filtragem de realce de imagens).

\subsection{Mapa de Densidade de Drenagem}

O mapa de densidade de drenagem foi gerado pela extração da rede de drenagem nas imagens orbitais, cálculo do parâmetro $\mathrm{Z}$ estimado pelos operadores de álgebras de mapas Conte e Média Zonal, ajuste e validação do modelo do semivariograma, aplicação da krigagem ordinária e, por fim, o fatiamento, gerando as classes de densidade de drenagem.

\subsection{Mapas de Vulnerabilidade e Favorabilidade à Erosão}

O método utilizado para gerar o mapa de vulnerabilidade à erosão foi baseado no conceito de Ecodinâmica de Tricart (1977), pela análise morfodinâmica da 
paisagem que compreende as interdependências e as inter-relações dos potencias de energia e de matéria (ALMEIDA et al., 1993), a partir da integração automática dos mapas de geologia, pedologia, geomorfologia e cobertura vegetal e uso da terra. Nesta análise, teve como suporte as imagens de satélite e as operações de álgebras de mapas: operadores zonais, que permitem estabelecer relações espaciais entre regiões de mapas distintos e operadores pontuais, que relacionam pontos individuais em diferentes mapas.

Esta integração automática classifica o grau de estabilidade ou instabilidade à erosão pela atribuição de valores de 1 a 3 , a partir da relação entre processos morfogenéticos e pedogenéticos. Quando predomina a pedogênese prevalece o processo formador de solo (estabilidade) e quando prevalece a morfogênese sobressae o processo formador do relevo (instabilidade). Na análise de cada classe dos mapas temáticos atribuiu-se um valor correspondente ao comportamento em relação aos processos denudacionais (Tabela 1).

Desta forma, as rochas com maior grau de coesão entre os minerais, o maior desenvolvimento do solo, os menores valores de declividade e a maior capacidade da cobertura na proteção da paisagem indicam que prevaleceu o processo pedogenético. Posteriormente, os valores de cada classe são integrados através da média aritmética, definindo, assim, as classes de vulnerabilidade à erosão.

Tabela 1. Valores correspondente ao comportamento em relação aos processos denudacionais

\begin{tabular}{|c|c|c|}
\hline Mapas & Classes temáticas & Pesos \\
\hline \multirow{6}{*}{$\begin{array}{l}\frac{\pi}{000} \\
\frac{0}{0} \\
0 \\
0\end{array}$} & Aluviões & $\mathbf{3 , 0}$ \\
\hline & Itaqueri & 2,6 \\
\hline & Serra Geral & 1,5 \\
\hline & Botucatu & 2,4 \\
\hline & Pirambóia & 2,5 \\
\hline & Corumbataí & 2,8 \\
\hline \multirow{7}{*}{ 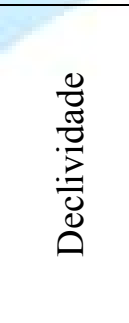 } & +2 & 1,0 \\
\hline & $2-5 \%$ & 1,3 \\
\hline & $5-10 \%$ & 1,7 \\
\hline & $10-20 \%$ & 2,0 \\
\hline & $20-30 \%$ & 2,3 \\
\hline & $30-50 \%$ & 2,3 \\
\hline & $>50 \%$ & $\mathbf{3 , 0}$ \\
\hline \multirow{6}{*}{$\begin{array}{l}\frac{\pi}{00} \\
\frac{0}{0} \\
\frac{0}{0} \\
0\end{array}$} & Neossolo Quartzarênico Órtico A Moderado & $3, \mathbf{0}$ \\
\hline & Gleissolo Tiomórfico Húmico & $\mathbf{3 , 0}$ \\
\hline & Argissolo Vermelho-Amarelo Eutrófico Típico text. média A moderado & 2,4 \\
\hline & Argissolo Vermelho-Amarelo Alumínico Típico text. média A moderado & 2,2 \\
\hline & Argissolo Vermelho-Amarelo Alissólico Típico text. média A moderado & 2,0 \\
\hline & Latossolo Vermelho-Amarelo Distrófico Típico text. média A moderado & 1,1 \\
\hline \multirow{6}{*}{$\begin{array}{l}\frac{\pi}{00} \\
0 \\
0 \\
00 \\
00 \\
0 \\
0 \\
0\end{array}$} & $\begin{array}{l}\text { Planície fluvial } \\
\end{array}$ & $3, \mathbf{0}$ \\
\hline & Topos convexos de dissecação baixa & 2,2 \\
\hline & Topos convexos de dissecação Média & 2,6 \\
\hline & Topos convexos de dissecação baixa & 3,0 \\
\hline & Topos tabulares de dissecação Média & 1,0 \\
\hline & Topos tabulares de dissecação Baixa & 1,2 \\
\hline
\end{tabular}




\begin{tabular}{|c|c|c|}
\hline \multirow{10}{*}{ 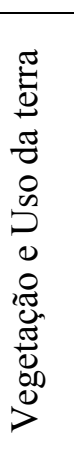 } & Veg. de Várzea & 20 \\
\hline & Mata & 1,6 \\
\hline & Cerrado & 2,1 \\
\hline & Capoeira & 1,9 \\
\hline & Cana-de-açúcar & 2,8 \\
\hline & Pastagem & 2,6 \\
\hline & Cultura perene & 2,7 \\
\hline & Cultura anual & 2,9 \\
\hline & Solo exposto & 3,0 \\
\hline & Área urbana & 3,0 \\
\hline
\end{tabular}

O mapa de favorabilidade à erosão foi realizado pelo método booleano, utilizando as classes dos mapas de densidade de drenagem e de erosividade. $\mathrm{O}$ método Booleano envolveu a combinação lógica de mapas binários através do operador condicional $\mathrm{E}$ e/ou $\mathrm{OU}$, segundo uma seqüência lógica para dar suporte a uma proposição pré-definida e gera dados com a representação temática, sendo a favorabilidade à erosão expressa espacialmente em forma de polígonos que representam classes favoráveis e não-favoráveis (Tabela 2).

Tabela 2. Operação booleana de reclassificação em classes favoráveis e não-favoráveis dos mapas de densidade de drenagem e de erosividade.

\begin{tabular}{|c|c|c|c|}
\hline $\begin{array}{c}\text { Classes de Densidade de } \\
\text { Drenagem }\end{array}$ & Reclassificação & $\begin{array}{c}\text { Classes de } \\
\text { Erosividade }\end{array}$ & Reclassificação \\
\hline Alta & Favorável & $7140-7280$ & Favorável \\
\hline Medianamente Alta & Favorável & $6890-7140$ & Favorável \\
\hline Medianamente Baixa & Não-favorável & $6645-6890$ & Não-favorável \\
\hline Baixa & Não-favorável & $6400-6645$ & Não-favorável \\
\hline
\end{tabular}

Este procedimento foi baseado em Moreira (2004), e a para sua aplicação foi necessário que as classes dos mapas representassem apenas duas classes, ou seja, que apresentassem um padrão binário. Esta generalização foi obtida através de uma reclassificação das diferentes classes para favorável e não favorável (Tabela 3). Após este procedimento foi realizada a operação booleana gerando a carta de favorabilidade à erosão. Os mapas de vulnerabilidade e favorabilidade à erosão podem ser vistos na Figura 2.

Tabela 3. Operação booleana de atribuição para geração do mapa de Favorabilidade

\begin{tabular}{|c|c|c|}
\hline $\begin{array}{c}\text { Classes de Densidade de } \\
\text { Drenagem }\end{array}$ & Classes de Erosividade & Classes de favorabilidade \\
\hline Favorável & Favorável & Alta \\
\hline $\begin{array}{c}\text { Não-favorável } \\
\text { Favorável }\end{array}$ & $\begin{array}{c}\text { Favorável } \\
\text { Não-favorável }\end{array}$ & Média \\
\hline Não-favorável & Não-favorável & Baixa \\
\hline
\end{tabular}




\begin{tabular}{|l|r|}
\hline Recebido em: $15 / 09 / 2005$ & HOLOS Environment, v.6 n.1, 2006 - P. 49 \\
\hline Liberado para Publicação em: $12 / 08 / 2006$ & ISSN: 1519-8634 \\
\hline
\end{tabular}

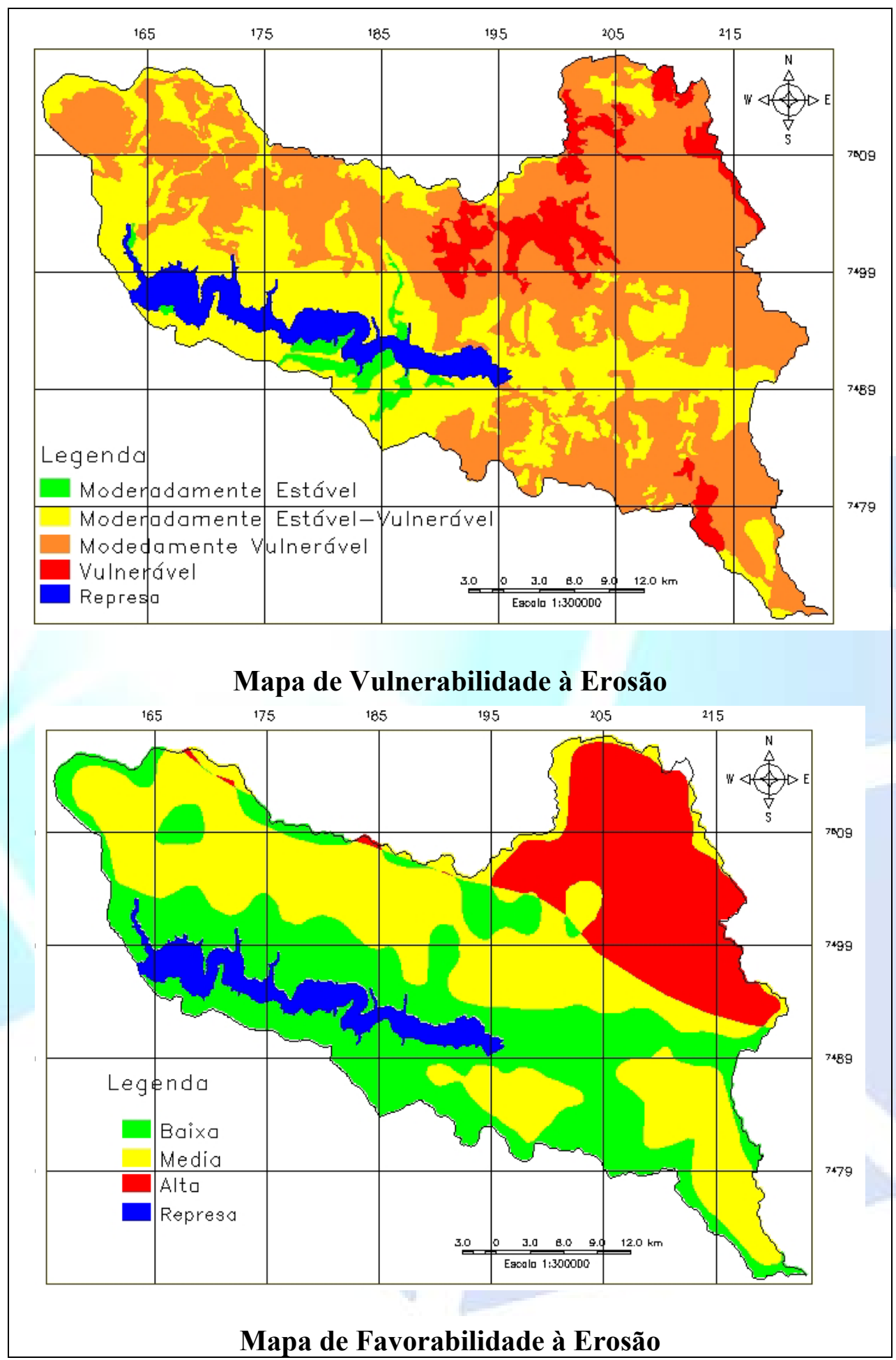

Figura 2- Mapas de vulnerabilidade e favorabilidade à erosão.

\subsection{Mapa de Sustentabilidade Territorial}

O mapa de sustentabilidade territorial foi gerado pelo método booleano, a partir das classes dos mapas de vulnerabilidade e favorabilidade à erosão. Neste procedimento, doze classes poderiam existir como resultado da sobreposição entre as classes dos referidos mapas, o que seria de difícil entendimento. Assim, elas foram 
agrupadas em quatro classes de sustentabilidade territorial (Tabela 4), para que efetivamente obtivesse uma síntese com os níveis de sustentabilidade de uso do território e não um conjunto de classes resultantes da interseção entre os polígonos de dois mapas temáticos (MEDEIROS, 1999).

Tabela 4. Operação booleana de atribuição para a geração do mapa de sustentabilidade territorial

\begin{tabular}{|c|c|c|}
\hline $\begin{array}{c}\text { Classes de } \\
\text { favorabilidade à erosão }\end{array}$ & $\begin{array}{c}\text { Classes de Vulnerabilidade à } \\
\text { erosão }\end{array}$ & $\begin{array}{c}\text { Classes de sustentabilidade } \\
\text { territorial }\end{array}$ \\
\hline Baixa & $\begin{array}{c}\text { Moderadamente-Estável } \\
\text { Moderadamente-Estável }\end{array}$ & Alta \\
Média & $\begin{array}{c}\text { Moderadamente Estável-Vulnerável } \\
\text { Moderadamente Estável } \\
\text { Moderadamente Estável }\end{array}$ & Baixa \\
\hline $\begin{array}{c}\text { Média } \\
\text { Alta }\end{array}$ & $\begin{array}{c}\text { Moderadamente Vulnerável } \\
\text { Moderadamente Vulnerável } \\
\text { Moderadamente Vulnerável } \\
\text { Vulnerável }\end{array}$ & Muito Baixa \\
\hline Baixa & $\begin{array}{c}\text { Vulnerável } \\
\text { Vulnerável }\end{array}$ & \\
\hline Baixa & & \\
\hline Alta & &
\end{tabular}

\section{RESULTADOS E DISCUSSÃO}

O mapa de sustentabilidade territorial (Figura 3) representa as áreas com distintas capacidades de suportar as atividades. A área foi obtida pelas características fisiográficas sem levar em consideração os aspectos sócio-econômicos. O modelamento segundo operadores de lógica booleana em SIGs é análogo à sobreposição de mapas em formato analógico em mesa de luz (overlay), método tradicionalmente utilizado em estudos relacionados às geociências. Devido à complexidade e a dimensão dos procedimentos envolvidos, foi fundamental a utilização de ferramentas de geoprocessamento para automatizar as tarefas repetitivas. 


\begin{tabular}{|l|r|}
\hline Recebido em: $15 / 09 / 2005$ & HOLOS Environment, v.6 n.1, 2006 - P. 51 \\
\hline Liberado para Publicação em: $12 / 08 / 2006$ & ISSN: 1519-8634 \\
\hline
\end{tabular}

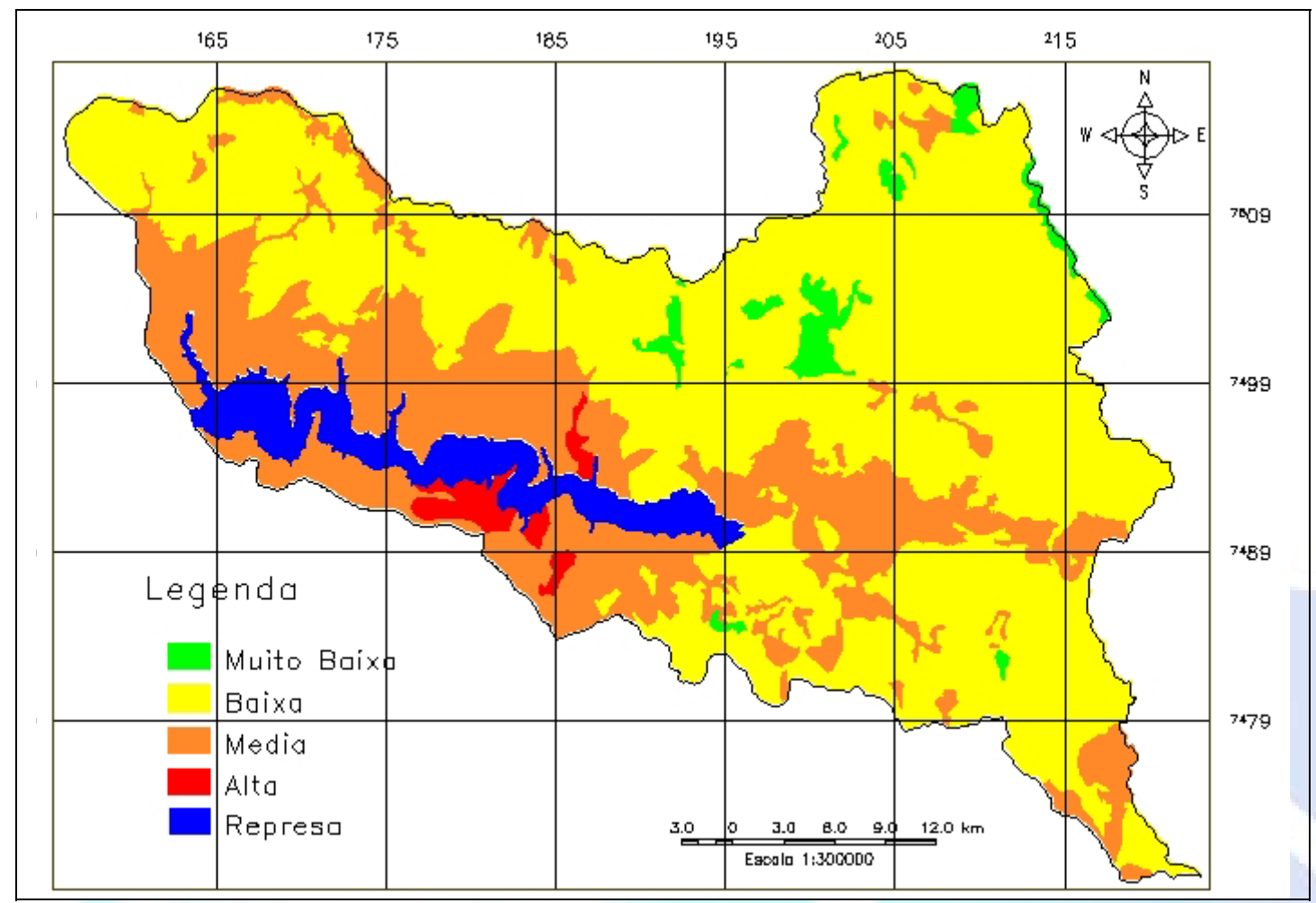

Figura 3. Mapa de sustentabilidade territorial.

Sem levar em consideração a área da Represa de Barra Bonita, as classes de Alta e Muito Baixa Sustentabilidade Territorial totalizam apenas 5\% e cobrem uma área de $24 \mathrm{~km}^{2}$ e $49 \mathrm{~km}^{2}$, respectivamente. A classe Média representa $30 \%$ da área $\left(440 \mathrm{~km}^{2}\right)$ e a classe dominante é a Baixa, com extensão aproximadamente de 950 $\mathrm{km}^{2}$, o que compõe $65 \%$ de toda a sub-bacia. Este resultado é decorrente, além dos aspectos fisiográficos naturais, da apropriação da área ao longo de sua história, decorrente de desmatamento acelerado e descompromissado com os princípios básicos de conservação à drenagem e solo e com a preservação da vegetação ciliar e das encostas serranas. As sínteses das características de cada classe são apresentadas na Tabela 5.

O mapa de sustentabilidade territorial representa uma importante ferramenta tecno-gerencial para a priorização dos ambientes a serem protegidos e auxilia no direcionamento ao manejo dos recursos disponíveis à um empreendimento. Sendo um produto essencial para a tomada de decisão, pois é um documento cartográfico que reflete a ocupação do território. No entanto, é importante ressaltar que, a classificação das unidades de sustentabilidade territorial varia com o tempo em virtude do caráter dinâmico dos componentes da paisagem. Assim, este produto, para que possa continuamente servir de subsídio às políticas de apropriação do território, deve ser facilmente gerado e permanentemente atualizado. Esses requisitos são satisfeitos quando utilizadas as geotecnologias de coleta, tratamento e análise de informação, como o instrumental utilizado neste trabalho. 
Tabela 5. Síntese das características de cada classe temática.

\begin{tabular}{|c|l|}
\hline \multirow{3}{*}{ Alta } & $\begin{array}{l}\text { Localizada nos solos LATOSSOLO VERMELHO-AMARELO e NEOSSOLO } \\
\text { QUARTZARENNICO, entre 2 e 5\% de declividade e inserida no relevo de Topo } \\
\text { Tabular de Dissecação Muito Baixa da Formação Pirambóia, com densidade de } \\
\text { drenagem Baixa, erosividade de 6645-6890 e com uma cobertura vegetal onde } \\
\text { predominam a mata e o cerrado. }\end{array}$ \\
\hline Média & $\begin{array}{l}\text { Concentra-se nas formações Pirambóia, Corumbataí e Aluviões, nos relevos de } \\
\text { topos Tabulares, Planícies de Inundação e Topos convexos de Dissecação Baixa, } \\
\text { em todos os tipos de solos, na faixa de erosividade 6645-6890, com declividade } \\
\text { de até 30\%, com densidade de drenagem Baixa a Medianamente Alta, nas áreas } \\
\text { de cana-de-açúcar e secundariamente em pastagens. }\end{array}$ \\
\hline Baixa & $\begin{array}{l}\text { Encontra-se em todas as formações e solos, em todos os relevos de Topos } \\
\text { Convexos, Topo Tabular de Dissecação Baixa e Planície Fluvial, em todas as } \\
\text { classes de declividades, mas principalmente nas classes maiores que 5\% com } \\
\text { predominância da classe 30 a 50\%, em todas as classes de erosividade e de } \\
\text { densidade de drenagem. A pastagem seguida da cana-de-açúcar são as principais } \\
\text { classes de uso da terra e as demais classes de uso da terra e vegetação natural } \\
\text { ocorrem espaçadas. }\end{array}$ \\
\hline Muito \\
Baixa & $\begin{array}{l}\text { Inserida nos relevos de Topos Convexos de Dissecação Baixa, Média a Baixa e e } \\
\text { Muito Alta da Formação Pirambóia de NEOSSOLO QUARTZARÊNICO e uma } \\
\text { pequena parte inserida nas formações Corumbatá, Botucatu, Serra Geral e } \\
\text { Itaqueri de LATOSSOLO VERMELHO-AMARELO com classes de declividade } \\
\text { entre 20 a 30\% e maior que 50\%, com densidade de drenagem Alta e } \\
\text { Medianamente Alta, erosividade de 6645-7280 e apresentando solo exposto, } \\
\text { cana-de-açúcar e pastagem. }\end{array}$ \\
\hline
\end{tabular}

Como a agricultura é um dos principais agentes propulsores do desenvolvimento econômico dos municípios da área de estudo, a implementação de um plano de gestão ambiental, em que a agricultura seja prioridade, constitui o caminho a percorrer para o desenvolvimento sócio-econômico. No entanto, a realidade da ocupação da área de estudo é adversa aos princípios de um desenvolvimento econômico sustentável, pois a apropriação do território pela atividade rural está inadequada com a capacidade do ambiente em sustentar esta atividade. As áreas com pastagem e cana-de-açúcar ocupam ambientes inapropriados, principalmente as regiões de várzea e as encostas das serras de São Pedro e Itaqueri. É neste contexto que se recomenda à recomposição da mata ciliar e o reflorestamento das encostas das serras de São Pedro e Itaqueri, segundo o Artigo $2^{\circ}$ da Lei 4.771 de 15 de setembro de 1965, do Código Florestal, modificado pela Lei 7.803 de 18 de Julho de 1989.

\section{CONCLUSÕES}

O mapa de sustentabilidade territorial foi gerado e foram definidas quatro classes: alta, média, baixa e muito baixa. As classes média e baixa sustentabilidade territorial perfizeram $95 \%$ da área de estudo. A área de estudo está sujeita a processos intensos de erosão e inundação, quiçá, escorregamentos, tendo em vista as 
características do meio natural e antrópico. A sistemática adotada mostrou-se eficiente, podendo ser utilizada como ponto de partida para estudos ambientais e de apropriação do território em consonância com o desenvolvimento sustentável.

\section{CONSIDERAÇÕES FINAIS}

O produto final dessa pesquisa é uma ferramenta de auxílio tanto para estabelecer diretrizes e prioridades de recuperação de áreas degradadas como para propor um nível de segurança adequado aos empreendimentos da agroindústria, já estabelecidos na região, e aos que venham a ser implementados.

Recomenda-se na área medidas de preservação principalmente nas áreas críticas ao desenvolvimento e aceleramento de processos geodinâmicos indesejáveis e a definição de locais apropriados para a localização de empreendimentos.

\section{REFERÊNCIAS}

ALMEIDA, F. F. M.; HASUI, Y.; PONÇANO, W. L.; DANTAS, A. S. L.; CARNEIRO, C. D. R.; MELO, M. S.; BISTRICHI, C. A. Mapa geológico do Estado de São Paulo: escala 1:500.000. São Paulo: IPT, 1981. 124p. (Monografia, $5)$.

ALMEIDA, J. R.; ZIMMERMANN, C. E.; RIVAIL, M. Planejamento ambiental: caminho para participação popular e gestão ambiental para nosso futuro comum, uma necessidade, um desafio. Rio de Janeiro: Thex, 1993. 176p.

ASRAR, G. Theory and applications of optical remote sensing. New York: John Wiley \& Sons, 1989. 734p.

CAMARGO, E; DRUCK, S. CÂMARA, G. Análise de superfície geoestatística superficial. São José dos Campos: INPE. Disponível em: $<$ http://www.inpe.br/livros.htm>. Acesso em: em 4 mar. 2004.

CAVALLI, A.C. Utilização de dados espectrais dos sensores TM/Landsat e AVHRR/NOAA-14 como indicadores de processos de degradação do solo. 1999. 153f. Tese (Doutorado em Geociências) - Instituto de Geociências e Ciências Exatas, Universidade Estadual Paulista, Rio Claro, 1999.

EMBRAPA. Sistema brasileiro de classificação do solo. Brasília: Serviço de Produção de Informação, 1999. 412p. 
EMBLETON, C.; LIEDTKE, B. Geomorphological mapping, remote sensing and terrain models. Zeitschrift fur Geomorphologie, n. 80, p. 1-5, Dec., 1990.

MEDEIROS, J. S. Banco de dados geográficos e redes neurais artificiais: tecnologias de apoio à gestão do território. 1999. 196f. Tese (Doutorado em Geografia) - Faculdade de Filosofia, Letras e Ciências Humanas, Universidade de São Paulo, São Paulo, 1999.

MONTEIRO, C. A. F. A dinâmica climática e as dunas no Estado de São Paulo: estudo geográfico sob forma de Atlas. São Paulo: IG, 2000. 1 CD.

MOREIRA, F. R. S. Uso e avaliação de técnicas de integração e análise espacial de dados em pesquisa mineral aplicadas ao Planalto de Poços de Caldas. 2001. São José dos Campos: INPE. Disponível em: <http://www.dpi.inpe.br/teses.html> Acesso em: 5 mar 2004.

OLIVEIRA, J. B.; CAMARGO, M. N., ROSSI, M.; CALDERADO FILHO, B. Mapa pedológico do Estado de São Paulo. Campinas: Instituto Agronômico, 1999. 4 mapas, color., $68 \mathrm{~cm} \times 98 \mathrm{~cm}$. Escala 1:500.000. Acompanha uma legenda expandida.

PONÇANO, W. L.; CARNEIRO, C. D. R.; ALMEIDA, F. F. M.; PRANDINI, F. L. Mapa geomorfológico do Estado de São Paulo: escala 1:500.000. São Paulo: IPT, 1981. 94p. (Monografia, 6).

ROSS, J. L. S.; MOROZ, I. C. Mapa geomorfológico do Estado de São Paulo: escala 1:500.000. São Paulo: USP;IPT;FAPESP, 1997. 64p.

SÃO PAULO (Estado) Secretaria de Recursos Hídricos, Saneamento e Obras. Programa de Investimentos para proteção e aproveitamento dos recursos hídricos das bacias dos rios Piracicaba, Capivari e Jundiaí. São Paulo: SABESP, 1999. 76p.

SCHOWENGERDT, R. A. Techiniques for image processing and classification in remote sensing. New York: Academic, 1983. 389p.

TRICART, J. Ecodinâmica. Rio de Janeiro: IBGE, 1977. 91p.

WESTEN, C. J.; RENGER, N.; TERLIEM, N. M. T.; SOETERS, R. Prediction of the occurrence of slope instability phenomena through GIS based hazard zonation. Geologische Rundschau, v.86, n.2, p. 404-414. 2000. 